\title{
The music listening preferences and habits of youths in Singapore and its relation to leisure noise-induced hearing loss
}

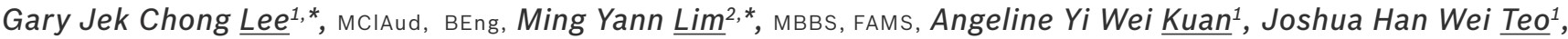 \\ Hui Guang $\underline{T^{1}{ }^{1}}$, Wong Kein $\underline{L O W}^{2}$, FRCS, PhD
}

\begin{abstract}
INTRODUCTION Noise-induced hearing loss (NIHL) is a preventable condition, and much has been done to protect workers from it. However, thus far, little attention has been given to leisure NIHL. The purpose of this study is to determine the possible music listening preferences and habits among young people in Singapore that may put them at risk of developing leisure NIHL.

METHODS In our study, the proportion of participants exposed to $>85 \mathrm{dBA}$ for eight hours a day (time-weighted average) was calculated by taking into account the daily number of hours spent listening to music and by determining the average sound pressure level at which music was listened to.

RESULTS A total of 1,928 students were recruited from Temasek Polytechnic, Singapore. Of which, $16.4 \%$ of participants listened to portable music players with a time-weighted average of $>85 \mathrm{dBA}$ for 8 hours. On average, we found that male students were more likely to listen to music at louder volumes than female students $(p<0.001)$. We also found that the Malay students in our study listened to louder music than the Chinese students $(p<0.001)$.

CONCLUSION We found that up to one in six young persons in Singapore is at risk of developing leisure NIHL from music delivered via earphones. As additional risks due to exposure to leisure noise from other sources was not taken into account, the extent of the problem of leisure NIHL may be even greater. There is a compelling need for an effective leisure noise prevention program among young people in Singapore.
\end{abstract}

Keywords: MP3 players, personal listening devices, portable music players, leisure noise-induced hearing loss, youths

\section{INTRODUCTION}

Hearing loss can affect functional ability. In children, hearing loss affects language development, speech, communication, and learning ability. In adults, hearing loss interferes with communication, causes social stigmatisation and leads to psychological problems such as low self-esteem and lack of confidence. Hearing loss also has economic ramifications, such as poorer job performance leading to personal loss of income, healthcare costs, and costs incurred due to the special education needs of the young with hearing loss.(1) Adult-onset hearing loss can result in serious national economic burdens and has been described as the fifteenth most serious health problem globally. ${ }^{(2)}$

Noise-induced hearing loss (NIHL) is a preventable cause of acquired hearing loss. Currently, much focus is directed to workplace NIHL. However, NIHL among the younger population due to exposure to leisure-time noise has become of increasing concern. ${ }^{(3)}$ In the United States, $12.5 \%$ of persons aged 6-9 years are estimated to have noise-induced hearing threshold shift in either one or both ears. ${ }^{(4)} \mathrm{A}$ German review of clinical data estimates that 1 in 10 adolescents have some degree of NIHL from leisure-time noise. ${ }^{(5)}$ A Chinese study on 120 young users of portable music players found impaired hearing in $14 \%$ of ears. ${ }^{(6)}$ In Singapore, a study among National
Service conscripts showed a hearing loss prevalence of 36 per 1,000 conscripts, especially those with frequent exposure to loud noise. ${ }^{(7)}$

There is the local perception that our youths are also being overly exposed to loud noise from the use of portable music players and visits to dance clubs and pubs. However, we do not have adequate data on this problem and scant attention has been paid to this issue. Thus, the aim of our study was to determine the prevalence of young people at risk of leisure NIHL in Singapore. To achieve the aim of our study, we studied noise exposure level from the use of portable music players among local polytechnic students.

\section{METHODS}

This study was approved by the Director of the School of Engineering, Temasek Polytechnic, Singapore. As 43\% of Singapore's Primary One cohort eventually enters one of the five polytechnics, the student profile found in polytechnics is representative of post-secondary youths in Singapore. ${ }^{(8)}$ Each year, the School of Engineering accepts approximately 2,000 freshmen to its various diploma courses. Freshmen were encouraged to participate in the present study by their lecturers and course managers. Students who agreed to participate were scheduled for the study according to the available slots in

\footnotetext{
${ }^{1}$ School of Engineering, Temasek Polytechnic, ${ }^{2}$ Department of Otolaryngology, Singapore General Hospital, Singapore

*These two authors contributed equally as first author in this work.

Correspondence: Mr Gary Jek Chong Lee, Head, Biomedical Engineering Diploma Unit, School of Engineering, Temasek Polytechnic, Singapore 529757. jekchong@tp.edu.sg
} 
Table I. Songs used in the sound test.

\begin{tabular}{lllc}
\hline Song & Language & Genre & $\begin{array}{c}\text { Sound pressure } \\
\text { level (dBA)* }\end{array}$ \\
\hline 'On the floor' & English & Rock & $52.3-106.0$ \\
'In the end' & English & Rock & $54.7-109.0$ \\
'Forget you' & English & Pop & $54.6-109.8$ \\
'Jai Ho' & English & Pop & $64.1-117.5$ \\
'Dragonforce' & English & Rock & $60.9-114.7$ \\
'I'm a loner' & Korean & Rock & $55.2-120.3$ \\
'Ring Ding Dong' & Korean & Pop & $55.2-110.0$ \\
'Gee' & Korean & Pop & $54.7-110.5$ \\
'Only you' & Chinese & Pop & $63.6-117.2$ \\
\hline${ }^{*}$ For volume setting of 1-30 & &
\end{tabular}

their class timetable. In addition, the study was also opened to students from other levels on a walk-in basis. Participation was voluntary and each participant was required to sign a consent form. Each participant received a Panasonic water bottle as a token of appreciation at the end of the study.

This study consisted of a self-administered questionnaire and a sound test. The self-administered questionnaire was used to determine: (a) age; (b) gender; (c) race; (d) duration (hours) of listening to portable music players; and (e) number of years of listening to portable music players. Portable music players included MP3 players, mobile phones with music players and any other portable device that uses earphones. Participants were also asked to report on the volume at which they listen to music, as well as exposure to other recreational noise. The sound test was conducted in a quiet laboratory in Temasek Polytechnic, with an ambient noise level of $35 \mathrm{dBA}$. To determine the usual volume at which each participant listens to music, participants were asked to select a song from a preselected list that was most representative of what he/she normally listened to. The list of songs used was based on the most popular songs listed on the websites of Gold 90.5 FM, YES 93.3 FM and 98.7 FM in April 2011, and a straw poll of 20 polytechnic students. With varied genres to reflect the music interests of the youths, a total of nine songs were chosen for the list; five songs in English, three in Korean and one in Chinese (Table I).

Participants were instructed to listen to a fixed 30-s portion of the chorus of the song they chose from the list, which was played using a standardised MP3 player. Each participant was asked to adjust the volume to a level that best approximated the average volume at which he/she typically uses to listen to music. The volume setting of each participant was noted. The music was administered via standardised, insert earphones.

The MP3 player used had previously been calibrated in a sound booth at the Biomedical Informatics Diploma Unit, Temasek Polytechnic, so that the equivalent A-weighted sound pressure level (i.e. dBA) of the different volume settings was known. This entailed the use of an Integrating Class 1 sound level meter (Model 1900; 3M Quest Technologies, Wisconsin, USA). In calibrating the volume setting to $\mathrm{dBA}$, the methodology
TWA $_{8 h r}>85 \mathrm{dBA} ; 16.4 \%$

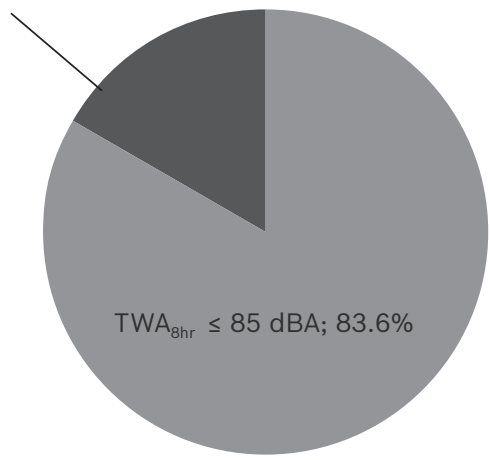

Fig. 1 Pie chart shows the proportion of students at risk of noiseinduced hearing loss at listening levels of $\mathrm{TWA}_{8 \mathrm{hr}}>85 \mathrm{dBA}$.

used by Catalano and Levin ${ }^{(9)}$ was applied in our study, albeit with some modifications. The right earpiece of each pair of earphones was connected to the sound level meter via a 2-cc coupler. To simulate the tight fit of the earpiece within the ear canal, Blu-Tack was used to seal the end of the earpiece onto the 2-cc coupler. The left earpiece was placed as far as possible (about $50 \mathrm{~cm}$ ) from the right earpiece and wrapped with a piece of cloth to prevent sound contamination. The test song was played for $30 \mathrm{~s}$ at volume setting 1, and the average A-weighted sound pressure level was obtained under the slow setting. This process was repeated from volume setting 2 to 30, which is the maximum. Table I shows the range of sound intensities (measured in $\mathrm{dBA}$ ) for each song at volume settings 1-30.

As all the participants had different listening sound levels and listened to music for varying durations each day, it was not possible to directly compare the potential impact of the noise exposure due to the use of their portable music players. In the occupational health setting, it is common practice to normalise a worker's exposure measurements to an 8-hour day. Based on the self-reported listening duration and the measured sound pressure level, the time-weighted average (TWA) for each student was calculated. TWA ${ }_{8 h r}$ is the equivalent sound level over 8 hours that would result in the same sound energy as the one calculated using the actual exposure time. Used to assess a worker's exposure to noise and determine what action should be taken, $\mathrm{TWA}_{8 \mathrm{hr}}$ is essential in international workplace safety and health regulations. $\mathrm{TWA}_{8 \mathrm{hr}}$ is computed by taking into account the measured sound level and the reported exposure time. Adopting the $3 \mathrm{~dB}$ exchange rate (equal energy rule) used by the Workplace Safety and Health (Noise) Regulation, Singapore, TWA $_{8 \mathrm{hr}}$ in the present study was computed using the following formula: ${ }^{(10)}$

$$
\mathrm{TWA}_{8 \mathrm{hr}}(\mathrm{dBA})=85+10 \log _{10}\left(\frac{T}{8} \times 2^{\frac{L-85}{3}}\right)
$$

where $T$ is the exposure time in hours, and $L$ is the listening sound pressure level of the noise $(\mathrm{dBA})$. 
Table II. Parameters examined, pertaining to music listening habits, stratified by gender.

\begin{tabular}{|c|c|c|c|c|c|c|c|c|c|c|}
\hline \multirow[t]{2}{*}{ Parameter } & \multicolumn{5}{|c|}{ Female participants } & \multicolumn{5}{|c|}{ Male participants } \\
\hline & $\begin{array}{l}\text { Chinese } \\
(n=567)\end{array}$ & $\begin{array}{l}\text { Malay } \\
(n=89)\end{array}$ & $\begin{array}{l}\text { Indian } \\
(n=29)\end{array}$ & $\begin{array}{l}\text { Others } \\
(n=26)\end{array}$ & $\begin{array}{c}\text { Total } \\
(n=711)\end{array}$ & $\begin{array}{l}\text { Chinese } \\
(n=923)\end{array}$ & $\begin{array}{c}\text { Malay } \\
(n=146)\end{array}$ & $\begin{array}{l}\text { Indian } \\
(n=91)\end{array}$ & $\begin{array}{l}\text { Others } \\
(n=57)\end{array}$ & $\begin{array}{c}\text { Total } \\
\text { ( } n=1,217)\end{array}$ \\
\hline $\begin{array}{l}\text { Mean reported } \\
\text { daily usage* (hrs) }\end{array}$ & 2.2 & 2.5 & 2.4 & 2.8 & 2.2 & 2.2 & 2.8 & 2.3 & 3.3 & 2.4 \\
\hline $\begin{array}{l}\text { Mean reported } \\
\text { prior usage* (yrs) }\end{array}$ & 4.8 & 5.2 & 4.8 & 5.2 & 4.9 & 4.8 & 5.6 & 4.7 & 5.7 & 4.9 \\
\hline $\begin{array}{l}\text { Mean listening } \\
\text { sound level (dBA) }\end{array}$ & 72.7 & 77.6 & 77.7 & 72.4 & 73.5 & 78.5 & 84.9 & 81.9 & 82.6 & 79.7 \\
\hline $\begin{array}{l}\text { Mean TWA }{ }_{8 \mathrm{hr}} \\
(\mathrm{dBA})\end{array}$ & 64.3 & 70.0 & 69.2 & 66.6 & 65.3 & 68.3 & 78.4 & 73.1 & 77.5 & 70.3 \\
\hline No. (\%) at risk ${ }^{+}$ & $47(8.3)$ & $12(13.5)$ & $6(20.7)$ & $2(7.7)$ & $67(9.4)$ & $167(18.1)$ & $47(32.2)$ & 19 (20.9) & $16(28.1)$ & $249(20.5)$ \\
\hline $\begin{array}{l}\text { No. }(\%) \text { reported } \\
\text { routinely listening } \\
\text { to music at or near } \\
\text { maximum volume }\end{array}$ & $53(9.3)$ & $18(20.2)$ & $11(37.9)$ & $5(19.2)$ & $87(12.2)$ & $159(17.2)$ & $42(28.8)$ & $22(24.2)$ & $17(29.8)$ & $240(19.7)$ \\
\hline
\end{tabular}

${ }^{*}$ Usage of portable music players. ${ }^{\dagger}$ At risk of hearing loss at TWA $>85 \mathrm{dbA}$. TWA 8 hr: time-weighted average over 8 hours

Table III. Parameters examined, pertaining to music listening habits, stratified by race.

\begin{tabular}{|c|c|c|c|c|c|}
\hline Parameter & $\begin{array}{c}\text { Chinese } \\
(n=1,490)\end{array}$ & $\begin{array}{c}\text { Malay } \\
(n=235)\end{array}$ & $\begin{array}{l}\text { Indian } \\
(n=120)\end{array}$ & $\begin{array}{l}\text { Others } \\
(n=83)\end{array}$ & $\begin{array}{c}\text { Total } \\
\text { (n = 1,928) }\end{array}$ \\
\hline Age (yrs) & 18.4 & 18.4 & 18.5 & 18.6 & 18.4 \\
\hline Mean reported prior usage* (yrs) & 4.8 & 5.4 & 4.7 & 5.5 & 4.9 \\
\hline Mean listening sound level (dBA) & 76.3 & 82.2 & 80.9 & 79.4 & 77.5 \\
\hline No. (\%) at risk ${ }^{+}$ & $215(14.4)$ & $59(25.1)$ & $25(20.8)$ & $18(21.7)$ & $316(16.4)$ \\
\hline $\begin{array}{l}\text { No. (\%) reported routinely listening } \\
\text { to music at or near maximum volume }\end{array}$ & $212(14.2)$ & $60(25.5)$ & $33(27.5)$ & $22(26.5)$ & $328(17.0)$ \\
\hline
\end{tabular}

${ }^{*}$ Usage of portable music players. ${ }^{\dagger}$ At risk of hearing loss at TWA $>85 \mathrm{dbA}$. TWA 8 hr: time-weighted average over 8 hours

Comparison of the average listening sound pressure levels between male and female students was performed using unpaired $t$-test. One-way analysis of variance (ANOVA) was used to compare the average listening sound pressure levels among the different racial groups. Levene's test was used to determine homogeneity in variances among the different racial groups. For all tests, $\mathrm{p}<0.05$ was considered statistically significant.

\section{RESULTS}

A total of 2,057 students were recruited for our study, but 129 students were excluded from analysis due to incomplete data. This resulted in a total of 1,928 viable participants, comprising 1,217 male students and 711 females. The typical age of the students ranged from 16 to 21 years, with an average of 18.4 years; there were two students aged $\geq 30$ years (aged 30 and 36 years, respectively). Of the 1,928 participants, 1,490 students were Chinese, 235 were Malay, 120 were Indian, and 83 were of other races. Tables II and III summarise the parameters examined pertaining to music listening habits in the present study, stratified by gender and race.

Of the 1,928 participants, an overwhelming $95.8 \%$ of them listen to some form of portable music player on a daily basis.
There is a wide range of self-reported duration of usage. On average, the participants listened to music 2.3 hours per day, with 32 claiming to listen to music for $>8$ hours per day. $17 \%$ of the participants reported routinely listening to their portable music players at or near the maximum volume. When the actual sound pressure levels of all the participants were measured, $533(27.6 \%)$ of them were found to listen to music on their portable music players at $>85 \mathrm{dBA}$. When normalised to an 8-hour day, $316(16.4 \%)$ of the students recorded a TWA $\mathrm{Thr}_{8 \mathrm{r}}$ of $>85 \mathrm{dBA}$ (Fig. 1).

Our analysis also found that, on average, male students tended to listen to music at louder volumes than female students (Fig. 2). $33 \%$ of male students listened to music at an average listening sound level of $>85 \mathrm{dBA}$, whereas only $18 \%$ of female students did the same. In all, a total of $20.5 \%$ of male students and $9.4 \%$ of female students were exposed to a $\mathrm{TWA}_{8 \mathrm{hr}}$ of $>85 \mathrm{dBA}$, which puts them at risk of hearing loss. We found that for the male students in our study, the mean sound level they listened to music at was $79.7 \mathrm{dBA}$, whereas that for the female students was $73.5 \mathrm{dBA}(\mathrm{p}<0.001)$.

Comparing the four racial groups with respect to the average sound level they listened to music at, we found that the mean listening sound level of $76.3 \mathrm{dBA}$ for Chinese students 


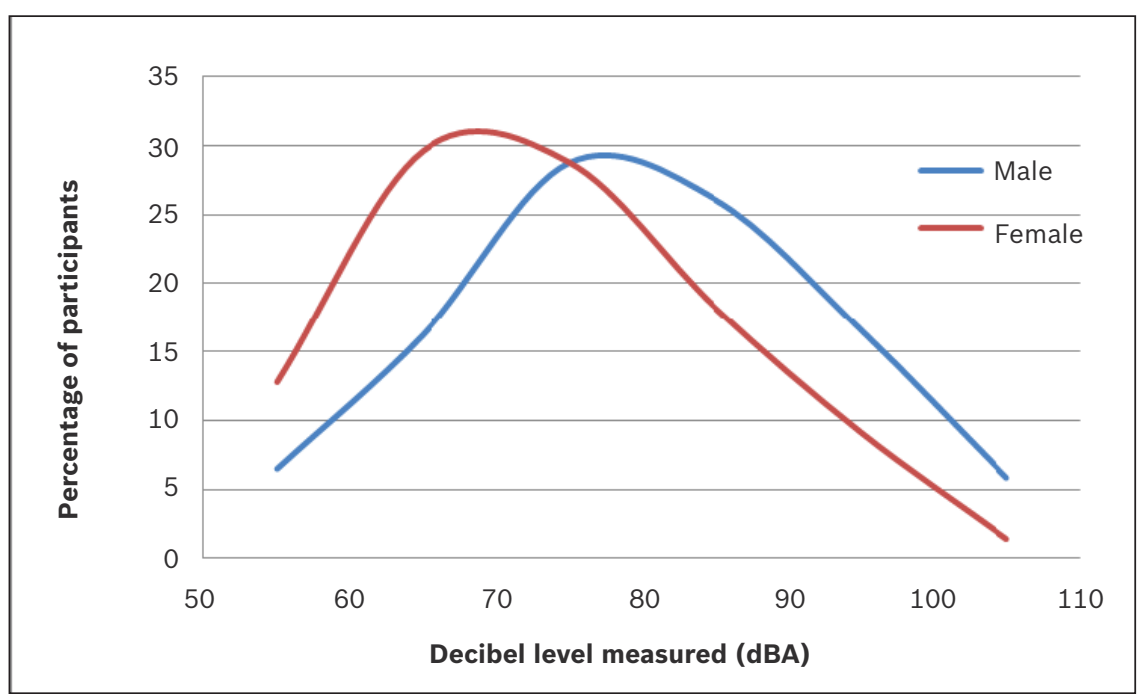

Fig. 2 Graph shows the distribution of listening sound levels of the two gender groups.

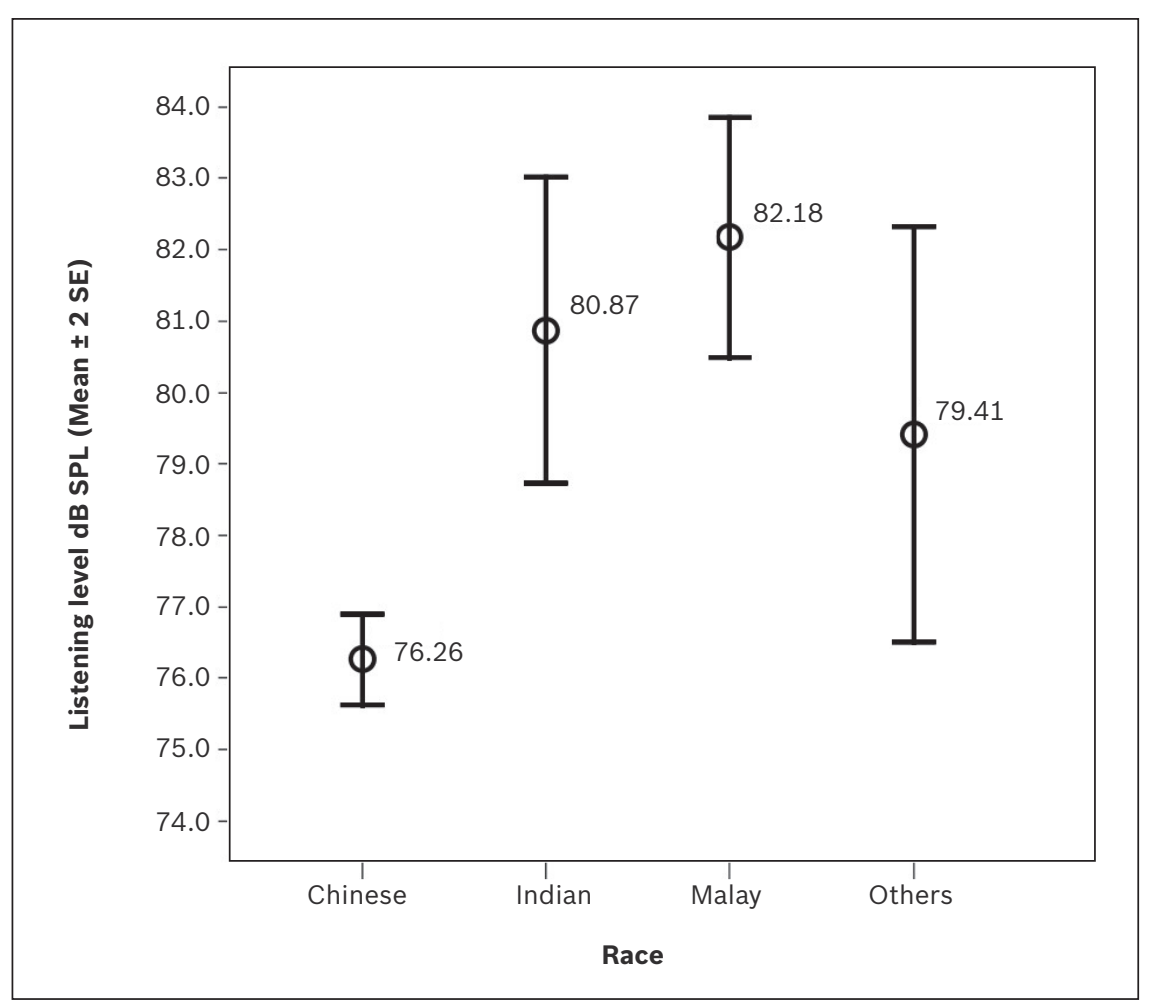

Fig. 3 Graph shows the mean listening sound levels of the different racial groups. SE: standard error; SPL: sound pressure level

was the lowest, and that for Malay students at $82.2 \mathrm{dBA}$ was the highest among the four racial groups (Fig. 3); Bonferroni multiple comparisons test revealed a statistically significant difference in listening sound levels between these two groups ( $p<0.001)$, but not between the other groups. Levene's test showed homogeneity in variances $(p<0.484)$, which determined that equal variances between groups could be assumed in conducting the Bonferroni analysis.

\section{DISCUSSION}

Sound is an essential medium by which we interact with others and our environment. Excessive noise, however, can be hazardous to health and cause temporary or permanent threshold shifts. Permanent threshold shifts may be due to microtrauma of hair cells, or damage to the tympanic membrane, ossicles or intracochlear membranes. These threshold shifts are not only socially disruptive, but also affect work performance. Excessive noise exposure can also lead to tinnitus, which may be disabling in some.

Rigorous regulations are in place to protect industrial workers from excessive noise. To protect workers from NIHL, Singapore's Workplace Safety and Health (Noise) Regulation states that workplaces with potential noise hazards should enforce a hearing conservation programme (HCP).(11) This includes identifying potential noise hazards, and implementing noise control measures, usage of hearing protectors and annual 
audiometric examinations. In most countries, it is generally agreed that a noise hazard exists when there is potential for an employee to be exposed to a sound level equivalent to or greater than $85 \mathrm{dBA}$ of noise over a period of 8 hours or more daily. The rationale behind this criteria is that when noise exposure goes beyond $85 \mathrm{dBA}$, the number of workers who will develop NIHL increases substantially; as noise exposure increases from $80 \mathrm{dBA}$ to $85 \mathrm{dBA}$, the number of workers who will develop NIHL increases from 1 per 100 to 8 per $100 .{ }^{(10)}$ When a sound level of $90 \mathrm{dBA}$ is reached, the incidence of $\mathrm{NIHL}$ rises to 25 per 100. ${ }^{(10)}$ The ISO (International Organization for Standardization) 1999 document further supports this with a prediction of the degree of NIHL sustained by a worker over a period of three years; at daily continuous noise exposure levels of $80 \mathrm{dBA}$, the median hearing loss is only $0.7 \mathrm{~dB}$ hearing level $(\mathrm{HL})$; this figure jumps appreciably to $2.9 \mathrm{~dB} \mathrm{HL}$ for daily continuous exposure at $85 \mathrm{dBA}$, and $6.5 \mathrm{~dB}$ HL for $90 \mathrm{dBA}$. $^{(12)}$

Although much has been done to protect workers from NIHL, little attention has been paid to leisure noise-induced damage. It is known that long-term use of portable music players can impair hearing function. ${ }^{(6)}$ In particular, MP3 players have been shown to produce significant elevation in hearing thresholds. ${ }^{(13)}$ The prevalence of youths at risk of NIHL from portable music players seems to vary, depending on geographical location and the profile of the youths studied. Among the 28 university students enrolled in a Canadian study, none were found to listen to MP3 players at a TWA ${ }_{8 \mathrm{hr}}$ level of more than $85 \mathrm{dBA} .{ }^{(14)}$ Conversely, a New York study on 189 college students revealed that $58.2 \%$ of the students listened to music on their MP3 players at a TWA ${ }_{8 \mathrm{hr}}$ level that exceeded $85 \mathrm{dBA} .{ }^{(15)}$ Anecdotally, there is increasing belief that the proportion of youth in Singapore susceptible to leisure NIHL is rising. However, until now, no objective data has been available to support this belief.

The present study is the first Singapore study that objectively examines the percentage of young people at risk of leisure NIHL from the use of a portable music player. Performed on a relatively larger scale compared to other studies, our study found that a significant percentage $(16.4 \%)$ of participants listened to music on their portable music players at a sound level exceeding the industrial and workplace $\mathrm{TWA}_{8 \mathrm{hr}}$ limit of $85 \mathrm{dBA}$. If we apply the projections for NIHL used for industrial noise based on exposure levels of TWA ${ }_{8 h r}$ more than $85 \mathrm{dBA}^{\text {, }}{ }^{(10)}$ it is predicted that $2.93 \%$ of youths will develop NIHL in their lifetime due to listening to music at high sound levels on portable music players. With births and new citizens in Singapore numbering at about 45,000 per year, ${ }^{(16)}$ this works out to 1,308 new cases of NIHL per year.

In comparison, $360(0.4 \%$ of the resident workforce tested $)$ NIHL cases due to excessive workplace noise are diagnosed each year. ${ }^{(17)}$ We believe that if stringent laws have been put in place to protect our workers from NIHL, comparable measures should also be taken by the Ministry of Health to protect our young. To best address this problem, the basic tenets of the Ministry of Manpower's HCP apply - education, hearing protection and audiometric screening; these are some of the possible measures that can be implemented.

Education will raise awareness of the problem of leisure NIHL among youths. In line with previous suggestions made in the United States, ${ }^{(18)}$ we propose compulsory implementation of hearing conservation curricula in all primary, secondary and tertiary schools in Singapore on a continuing basis. Such a measure may not require heavy financial investment; it can simply be a short session held by the school annually, to demonstrate the evidence of NIHL and its consequences, and to encourage responsible music listening behaviour. Schools could invite previous "sufferers" of leisure NIHL to give talks and share their experiences. Visiting school nurses could also play an important role in the education process. ${ }^{(19)}$

Interestingly, in keeping with the typical high-risk behaviour of young males, ${ }^{(20)}$ our results showed that the male students in our study were significantly more likely to listen to music at a louder volume than female students. Differences among the different races with regard to their music listening behaviour were also noted. In particular, the Malay students in the present study seemed to listen to music at a louder volume than students of other races. The sound pressure level at which Malay students listened to music was significantly different than that of the Chinese students. While the education process should target all young people, particular attention should be paid to these subgroups of young students.

Audiometric examination is an important part of HCP. As the signs and symptoms of NIHL are not apparent until a significant threshold shift has occurred, periodic audiometric examination can help to detect hearing loss at an early stage. Early detection of hearing loss will provide an opportunity for immediate measures to be taken to prevent further hearing loss. This is the basis upon which industries monitor their workers as part of HCPs. While performing regular audiograms for all youths in Singapore may not be feasible, otoacoustic emission tests have been proposed as a rapid means of detecting early noise induced damage, and may be a viable screening test for early NIHL. ${ }^{(21)}$ Further studies are warranted before such a screening test can be implemented nationwide.

One possible weakness in our study is the fact that participants may over- or under-report the number of hours they spend listening to their portable music players each day. This will affect the TWA ${ }_{8 h r}$ computation. Other than that, asking participants to adjust the volume of the music according to their usual preferred listening sound level in a laboratory could be subject to recall bias. A possible alternative to this would be to study students listening to portable music players on the spot. However, while this may eliminate the artificiality of a test, such a methodology may result in the recruitment of only a restricted number of students, and may also have a selection bias for more 'avid' music listeners. Another limitation of our 
study is that other sources of noise exposure were not taken into account in our calculations. Many youths engage in numerous other activities such as rock concerts, dance clubs, pubs, computer games and other co-curricular activities, which would certainly contribute to further noise-induced damage. Therefore, the extent of leisure NIHL may be even greater than that suggested by this study. This makes the need for implementation of effective leisure noise prevention programmes even more compelling. Of note, no audiometric tests were performed as part of the present study. Having the audiograms of the participating students may have allowed us to correlate hearing status to dose of noise exposure.

In conclusion, this study on the music listening preferences and habits of youths who listen to music on portable music players, delivered through earphones, revealed that up to one in six youths in Singapore is at risk of developing leisure NIHL. Gender and racial factors play a part in leisure NIHL; male students were found to be at higher risk than female students, and Malay students were found to be at higher risk than Chinese students. As the present study did not take into account additional risks resulting from leisure noise exposure from other sources, the extent of leisure NIHL may be even greater than that suggested by the results of this study. We suggest a nationwide, Ministry-coordinated study to validate our results.

\section{ACKNOWLEDGEMENT}

The authors would like to acknowledge Panasonic Systems Asia Pacific for the provision of three television sets as part of a lucky draw, as well as a free water bottle, for all the participants.

\section{REFERENCES}

1. Low WK, Pang KY, Ho LY, Lim SB, Joseph R. Universal newborn hearing screening in Singapore: the need, implementation and challenges. Ann Acad Med Singapore 2005; 34:301-6.

2. Nelson DI, Nelson RY, Concha-Barrientos M, Fingerhut M. The global burden of occupational noise-induced hearing loss. Am J Ind Med 2005; 48:446-58.

3. Dalton DS, Cruickshanks KJ, Wiley TL, et al. Association of leisure-time noise exposure and hearing loss. Audiology 2001; 40:1-9.

4. Niskar AS, Kieszak SM, Holmes AE, et al. Estimated prevalence of noise- induced hearing threshold shifts among children 6 to 19 years of age: the Third National Health and Nutrition Examination Survey, 1988-1994, United States. Pediatrics 2001; 108:40-3.

5. Zenner HP. [Leisure time noise. Hearing damage in every 10 th adolescent is possible]. HNO 1999; 47:225. German.

6. Peng JH, Tao ZZ, Huang ZW. Risk of damage to hearing from personal listening devices in young adults. J Otolaryngol 2007; 36:181-5.

7. Toh ST, Lu P, Ong M, Seet B. Prevalence of hearing disorders in Singapore military conscripts: a role for routine audiometry screening? Singapore Med J 2002; 43:622-7.

8. Ministry of Education. Speech by Mr Heng Swee Keat, Minister for Education, at Ngee Ann Polytechnic 50th Anniversary Celebrations Launch Event on 25 Apr 2013, 1700 hrs, Ngee Ann Polytechnic Convention Centre. In: Ministry of Education, Singapore: Speeches [online]. Available at: http://www. moe.gov.sg/media/speeches/2013/04/25/speech-by-mr-heng-swee-keatat-ngee-ann-polytechnic-50th-anniversary-celebrations-launch-event.php. Accessed September 3, 2013.

9. Catalano PJ, Levin SM. Noise-induced hearing loss and portable radios with headphones. Int J Pediatr Otorhinolaryngol 1985; 9:59-67.

10. US Department of Health and Human Services. Occupational Noise Exposure-Revised Criteria 1998. Ohio: National Institute for Occupational Safety and Health; 1998.

11. Ministry of Manpower, Singapore. Workplace Safety and Health Guidelines. Hearing Conservation Programme. Singapore: Ministry of Manpower; 2010.

12. International Organization for Standardization. Acoustics - Determination of occupational noise exposure and estimation of noise-induced hearing impairment. Geneva: International Organization for Standardization, 1990.

13. Kim MG, Hong SM, Shim HJ, et al. Hearing threshold of Korean adolescents associated with the use of personal music players. Yonsei Med J 2009; 50:771-6.

14. McNeill K, Keith SE, Feder K, Konkle AT. Michaud DS. MP3 player listening habits of 17 to 23 year old university students. J Acoust Soc Am 2010; 128:646-53.

15. Levey S, Levey T, Fligor BJ. Noise exposure estimates of urban MP3 player users. J Speech Lang Hear Res 2011; 54:263-77.

16. Singapore Department of Statistics. Census of the population 2010. Advance Census Release. Singapore: Ministry of Trade \& Industry; 2010.

17. Manpower Research and Statistics Department. Singapore Yearbook of Manpower Statistics, 2010. Singapore: Ministry of Manpower; 2010.

18. Folmer RL, Griest SE, Martin WH. Hearing conservation education programs for children: a review. J Sch Health 2002; 72:51-7.

19. Folmer RL. The importance of hearing conservation instruction. J Sch Nurs 2003; 19:140-8.

20. Harris CR, Jenkins M, Glaser D. Gender Differences in Risk Assessment: Why do Women Take Fewer Risks than Men? Judgment and Decision Making 2006; 1:48-63.

21. Helleman HW, Jansen EJ, Dreschler WA. Otoacoustic emissions in a hearing conservation program: general applicability in longitudinal monitoring and the relation to changes in pure-tone thresholds. Int J Audiol 2010; 49:410-9. 